\title{
5-year-old girl with bilateral lower leg pain
}

\section{Kloth $^{1} \cdot$ T. Wowra ${ }^{2} \cdot$ D. Vogele ${ }^{1} \cdot$ M. Beer ${ }^{1} \cdot$ S. A. Schmidt ${ }^{1}$}

Published online: 3 June 2020

(C) ISS 2020

\section{History}

Five year-old girl with bilateral pain of the lower legs and pelvis for 4 weeks. Further symptoms were eyelid edema, swollen lips and a butterfly erythema on the face. Further elevated values for creatine kinase, muscle enzymes, troponin and LDH were registered, suggesting autioimmune process (Figs. 1, 2, 3 and 4).

C. Kloth and T. Wowra contributed equally to this work.

The diagnosis can be found at https://doi.org/10.1007/s00256-02003477-x

C. Kloth

christopher.kloth@uniklinik-ulm.de

1 Department for Diagnostic and Interventional Radiology, University Hospital Ulm, Albert-Einstein-Allee 23, 89081 Ulm, Germany

2 Department of Pediatrics and Adolescent Medicine, University Hospital Ulm, Eythstrasse 24, 89075 Ulm, Germany

\section{Compliance with ethical standards}

Ethical approval All procedures performed in studies involving human participants were in accordance with the ethical standards of the institutional and/or national research committee and with the 1964 Helsinki declaration and its later amendments or comparable ethical standards.

Conflict of interest The authors declare that they have no conflicts of interest.

Publisher's note Springer Nature remains neutral with regard to jurisdictional claims in published maps and institutional affiliations.

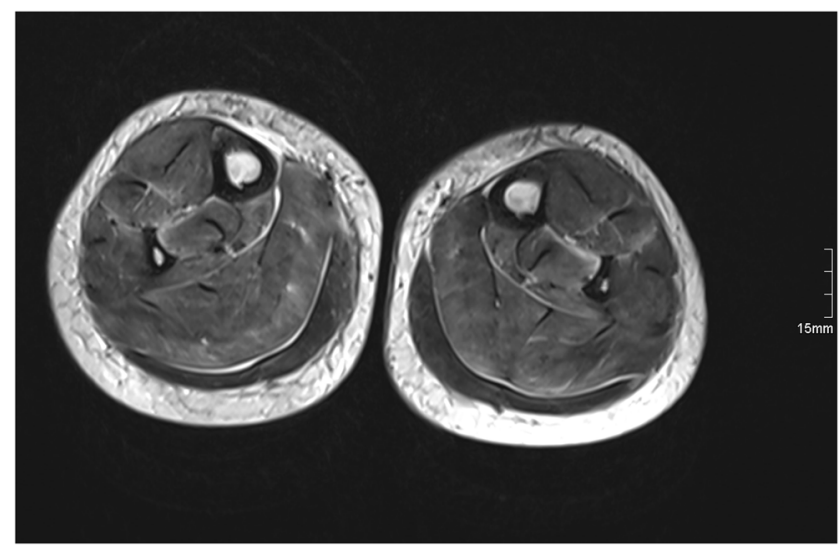

Fig. 1 Axial T2w MRI image of the pelvis and the extremities without contrast agent. MRI imaging was performed 2 days after admission 


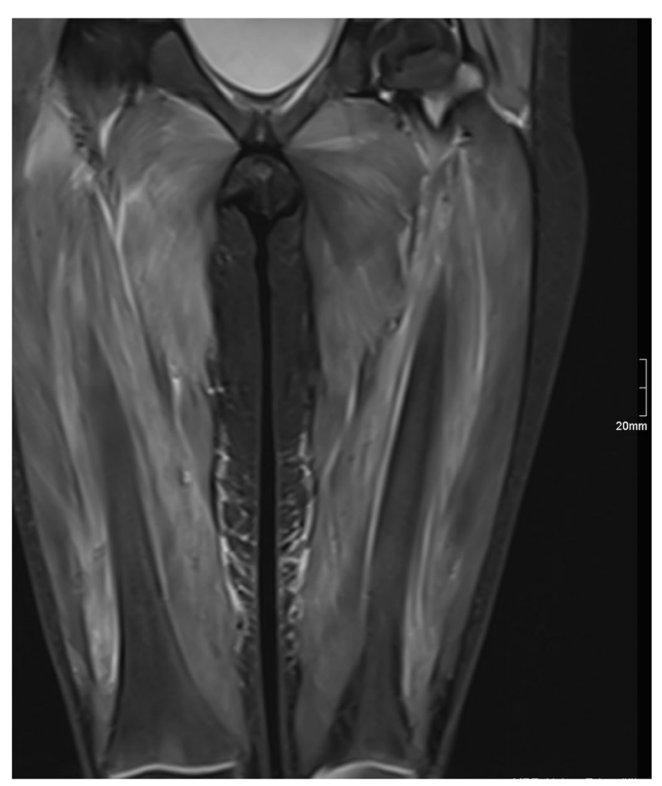

Fig. 2 Coronal TIRM MRI image of the thighs

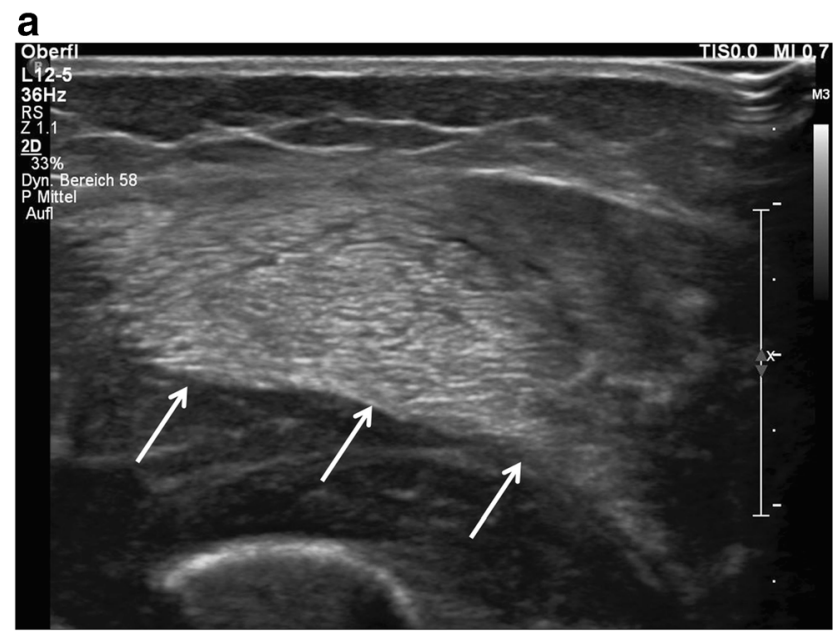

b

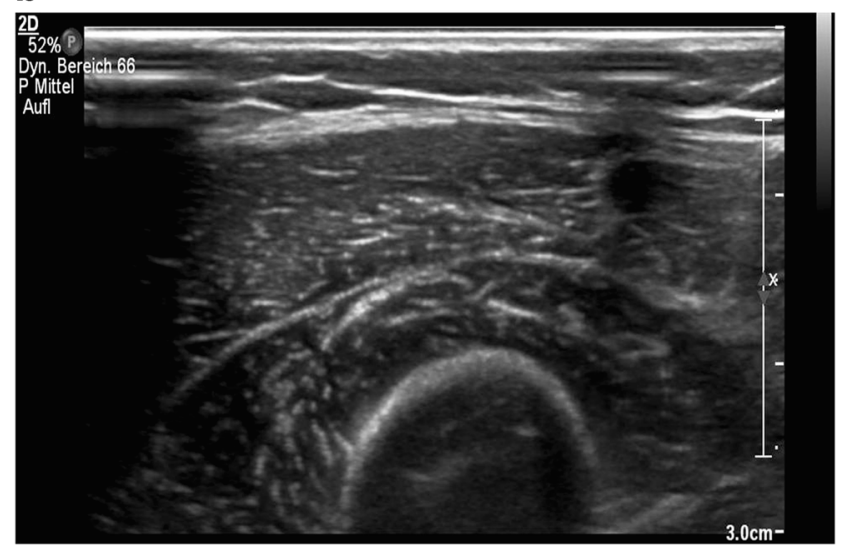

Fig. 3 a und b: - First Ultrasound imaging 6 days after admission with a high-resolution $12.5 \mathrm{MHz}$ transducer of superficial musculus quariceps femoris $\bullet$ Ultrasound imaging after 5 weeks under therapy

\section{a}

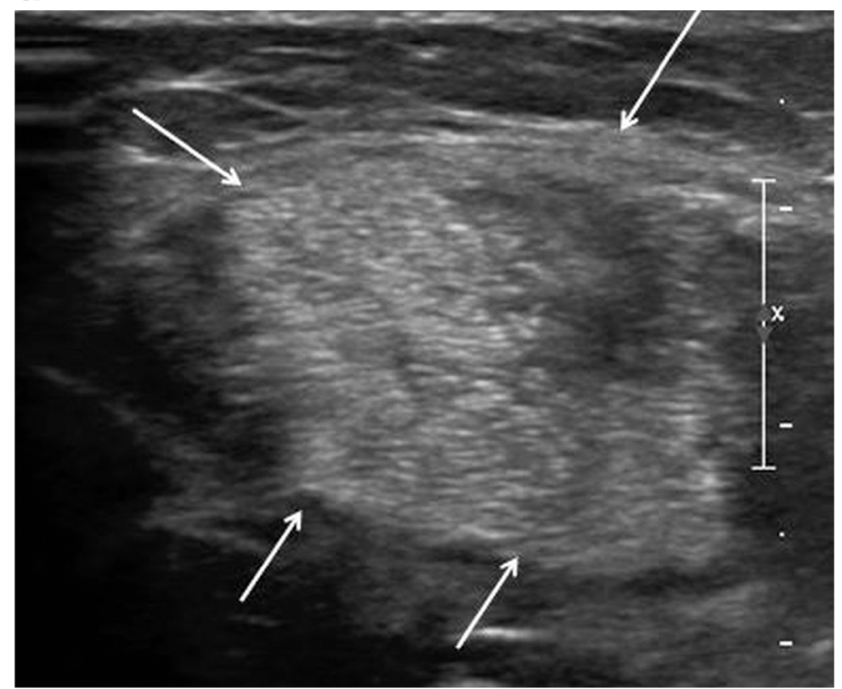

b

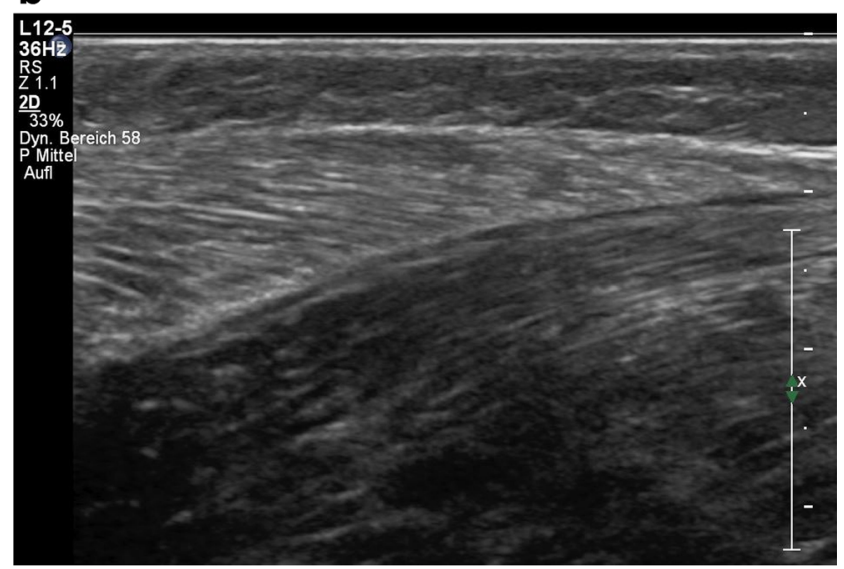

Fig. 4 a Ultrasound with a high-resolution $12.5 \mathrm{MHz}$ transducer of superficial M. gastrocnemius. b Ultrasound imaging after 5 weeks 